\title{
Hepatitis E virus seroepidemiology: a post- earthquake study among blood donors in Nepal
}

\author{
Ashish C. Shrestha ${ }^{1,2}$, Robert L. P. Flower ${ }^{1}$, Clive R. Seed ${ }^{3}$, Manita Rajkarnikar ${ }^{4}$, Shrawan K. Shrestha ${ }^{4}$, Uru Thapa $^{4}$, \\ Veronica C. Hoad ${ }^{3}$ and Helen M. Faddy ${ }^{1,2^{*}}$
}

\begin{abstract}
Background: As one of the causative agents of viral hepatitis, hepatitis E virus (HEV) has gained public health attention globally. HEV epidemics occur in developing countries, associated with faecal contamination of water and poor sanitation. In industrialised nations, HEV infections are associated with travel to countries endemic for $\mathrm{HEV}$, however, autochthonous infections, mainly through zoonotic transmission, are increasingly being reported. HEV can also be transmitted by blood transfusion. Nepal has experienced a number of HEV outbreaks, and recent earthquakes resulted in predictions raising the risk of an HEV outbreak to very high. This study aimed to measure HEV exposure in Nepalese blood donors after large earthquakes.
\end{abstract}

Methods: Samples $(n=1,845)$ were collected from blood donors from Kathmandu, Chitwan, Bhaktapur and Kavre. Demographic details, including age and sex along with possible risk factors associated with HEV exposure were collected via a study-specific questionnaire. Samples were tested for HEV IgM, lgG and antigen. The proportion of donors positive for HEV IgM or IgG was calculated overall, and for each of the variables studied. Chi square and regression analyses were performed to identify factors associated with HEV exposure.

Results: Of the donors residing in earthquake affected regions (Kathmandu, Bhaktapur and Kavre), 3.2\% (54/1,686; 95\% Cl 2.7-4.0\%) were HEV IgM positive and two donors were positive for HEV antigen. Overall, 41.9\% (773/1,845; 95\% Cl 39.7-44.2\%) of donors were HEV IgG positive, with regional variation observed. Higher HEV IgG and IgM prevalence was observed in donors who reported eating pork, likely an indicator of zoonotic transmission. Previous exposure to HEV in Nepalese blood donors is relatively high.

Conclusion: Detection of recent markers of HEV infection in healthy donors suggests recent asymptomatic HEV infection and therefore transfusion-transmission in vulnerable patients is a risk in Nepal. Surprisingly, this study did not provide evidence of a large HEV outbreak following the devastating earthquakes in 2015.

Keywords: Blood donor, Earthquake, Hepatitis E virus, Hepatitis, Jaundice

\section{Background}

Hepatitis E virus (HEV) has gained public health attention as one of the causative agents of viral hepatitis. The four genotypes of this non-enveloped RNA virus differ in mode of transmission and geographical occurrence [1, 2]. In developing countries, major outbreaks of HEV with

\footnotetext{
* Correspondence: hfaddy@redcrossblood.org.au

${ }^{1}$ Research and Development, Australian Red Cross Blood Service, 44 Musk

Avenue, Kelvin Grove, Brisbane, QLD 4059, Australia

${ }^{2}$ School of Medicine, The University of Queensland, 288 Herston Road, Herston, Brisbane, QLD 4006, Australia

Full list of author information is available at the end of the article
}

genotypes 1 and 2 are associated with transmission via the faecal-oral route [1, 3]. In developed countries, HEV has traditionally been associated with travel to countries endemic for HEV [4, 5], however, locally acquired HEV infections, associated with zoonotic transmission, are increasingly reported in such countries [5-8].

In Nepal, regular HEV outbreaks have occurred during the previous 4 decades, with reported outbreaks in 1973, 1981-1982, 1987, 1995 and 2014 [9-11]. During these outbreaks, a maternal mortality rate of $21-25 \%$ was reported [9]. During an outbreak in Biratnagar in 2014, 
the case fatality rate was $0.2 \%$ [11]. HEV IgG prevalence in 1999-2000 was estimated to be $38 \%$ among the general population of Nepal [9]. Kathmandu was designated hyper-endemic for HEV, with rural areas non-endemic [9]. A recent study has demonstrated HEV IgG prevalence of $47 \%$ among patients visiting a hospital in Kathmandu [12]. HEV infections have also been reported in travellers to Nepal [13-15]. Poor infrastructure development in terms of water supply and sewerage systems can facilitate the contamination of drinking water [16], especially during the summer monsoon season [17]. Epidemics have been associated with faecal contamination of water, and molecular characterization has shown genotype 1 as a cause of acute HEV infection [18]. HEV antibodies and RNA have been detected in farm swine from Kathmandu [19], indicating the possibility of zoonotic transmission in addition to the usual faeco-oral route.

The recent devastating earthquakes that occurred on 25th April and 12th May 2015 in Nepal raised concerns that the risk of an imminent HEV outbreak was very high, with HEV possibly causing up to 510 deaths in pregnant women [20]. During these earthquakes and their aftermath, 8,891 people lost their lives [21], with many left homeless having to share common shelter under tents for months. Under such overcrowded living conditions poor sanitation and hygiene were likely and individuals no doubt had limited access to safe drinking water, contributing to increased potential for infectious disease outbreaks [20, 22]. The burden of HEV at this time was also expected to be high due to the approaching summer monsoon season and limited access to health facilities [20,23]. We therefore sought to estimate the rate of previous and recent HEV infection in Nepalese blood donors in the months following the large earthquakes. This study aimed to provide surveillance data about HEV in Nepal, determine the possible impact of the recent earthquakes through serological evidence of recent HEV exposure, and analyse variables as possible risk factors for exposure to HEV.

\section{Methods}

\section{Sample population}

A total of 1,845 blood donors eligible to donate blood as per the criteria of the Central Blood Transfusion Service (CBTS), Nepal Red Cross Society (NRCS) were included in this study. A cross section of samples were collected at blood transfusion services in Kathmandu $(n=1,435)$, Chitwan $(n=159)$, Bhaktapur $(n=135)$, and Kavre $(n=116)$, during the months June-September, 2015. The required sample size for Kathmandu was estimated, using standard methods [24], to be 1,448, based on the assumption of 38\% HEV IgG prevalence [9], 95\% confidence interval, and an absolute precision of $2.5 \%$. Sample numbers from the other districts were based on accessibility to the donor population.

\section{Sample collection}

Blood donor samples were collected in BD Vacutainer ${ }^{\circ}$ PPT Plasma Preparation Tubes (Becton, Dickson and Company (BD) Biosciences, San Diego, USA). Samples were centrifuged at 2,500 $\mathrm{rpm}$ for $5 \mathrm{~min}$ before storage at $-20{ }^{\circ} \mathrm{C}$ until testing.

\section{Variables obtained through additional questionnaire}

In order to identify possible risk factors associated with HEV exposure, the following variables were included in the additional questionnaire:

1. Donor status: Donors who had previously donated were categorised as repeat donors and those who were donating for the first time as new donors.

2. History of jaundice: Jaundice was defined as any known feature of jaundice including yellow discolouration of skin and hepatitis, whether or not a donor required medical support. Family member jaundice referred to when any family member of a donor had jaundice, as defined above.

3. Source of drinking water: Donors were asked about their drinking water source, whether it be from a community tap, municipality tap, or underground. Community tap refers to a common tap in the community with a reservoir tank in that local area. Municipality tap is treated/purified and is usually supplied to the home by the local government authority. An underground source refers to any ground water source including hand-pumps and wells. Donors responding to two or more options were categorised as relying on multiple sources. Those reporting sources other than those mentioned above including bottled water were categorised as 'other'.

4. Drinking water treatment method: Donors were asked how they treated water for drinking purposes, which included: boiling (boiling water prior to drinking); filtering (filtration of water); chemical treatment (use of water purifier chemicals); or, no treatment (drinking directly from source). Donors with multiple options selected were categorised as multiple methods.

5. Vegetarianism: Donors who ate meat were categorised as non-vegetarian, while others were categorised as vegetarian.

6. Pork consumption: Non-vegetarians who ate pork were categorised as pork consumers and others as pork non-consumers.

7. International travel: Donors who had travelled to other countries were categorised as international 
travellers, while those who had not, as non-travellers.

\section{Sample testing}

All samples were de-linked prior to testing. Plasma samples were tested individually for HEV IgM (Wantai HEV-IgM ELISA, Beijing Wantai Biological Pharmacy Enterprise Co., Ltd, Beijing, China), as per the manufacturer's instructions. Any samples testing positive were re-tested in duplicate. Samples that were reactive two or three times were reported as HEV IgM positive. All samples were also tested for HEV-IgG (Wantai HEV IgG ELISA, Beijing Wantai Biological Pharmacy Enterprise Co., Ltd) and HEV antigen (Wantai HEV-Ag ${ }^{\text {Plus }}$ ELISA, Beijing Wantai Biological Pharmacy Enterprise Co., Ltd) as per the manufacturer's instructions, using the same testing algorithm as mentioned above for HEV IgM.

\section{Statistical analysis}

Donor data obtained from the questionnaire were entered in to a Microsoft Excel 2010 (Redmond, WA, USA) database. Proportions of donors HEV IgG, IgM or antigen positive were calculated overall and for each of the study variables, and 95\% confidence intervals estimated. IBM SPSS Statistics 23 (IBM Centre, NSW, Australia) was used to analyse for statistical inference (chi-square, odds ratio) and to determine association with variables. Some donors did not answer some of the questions on the questionnaire, resulting in missing data for some variables. In these instances, the missing data were subjected to multiple imputations prior to regression analyses. Thus, in the absence of data from donors not responding to the study variables, potential bias in the inference could not be excluded. In addition, donors' responses to the questions were based on recollection, introducing the risk of possible recall bias.

\section{Results}

Of the 1,845 samples tested, 55 (3.0\%, 95\% CI 2.2-3.8\%) were positive for HEV IgM. The proportion of donors with both HEV IgM and IgG was $2.7 \%$. HEV IgM prevalence was associated with a donor reporting having a history of jaundice or reporting pork consumption $(p<0.05)$ (multivariate analysis) (Table 1 ). No associations were observed for the other factors investigated (Table 1). Of the donors residing in earthquake affected regions (Kathmandu, Bhaktapur and Kavre), 3.2\% (95\% CI 2.7-4.0\%) of donors were HEV IgM positive, and two donors were positive for $\mathrm{HEV}$ antigen. These $\mathrm{HEV}$ antigen positive individuals were also HEV IgG positive (Table 2), but negative for HEV IgM. Both HEV antigen positive donors were from Kathmandu and 36 years of age.
HEV IgG was detected in 773 of the 1,845 samples tested $(41.9 \%, 95 \%$ CI 39.7-44.2\%). The prevalence was significantly higher $(p<0.05)$ in Bhaktapur, Kavre and Kathmandu than the Chitwan district (Table 3). HEV IgG prevalence increased with increasing age and was highest $(85.7 \%)$ in individuals above 55 years $(p<0.05)$. HEV IgG prevalence was also higher in repeat blood donors, those with a history of jaundice and those reporting pork consumption $(p<0.05)$ (multivariate analysis) (Table 3 ). Individuals who relied on drinking underground water were associated with having a lower HEV IgG prevalence $(p<0.05)$ (multivariate analysis) (Table 3).

\section{Discussion}

HEV outbreaks occur sporadically in developing countries due to faecal contamination of water and poor sanitation [25]. Given a relatively high mortality rate $(0.2-4 \%)$, which is particularly high in pregnant women (10-25\%) [17], HEV is a topic of public health concern in developing countries. Recent devastating earthquakes in Nepal could have facilitated an outbreak of HEV. In this study, we measured previous and current HEV infection in Nepalese blood donors after recent major earthquakes to provide surveillance data on HEV in Nepal and to determine possible risk factors for HEV exposure.

This study was conducted during the months JuneSeptember, 2015, after the devastating earthquakes and the monsoon season period, when waterborne outbreaks of HEV were likely to occur [20, 26]. Bhaktapur, Kavre and Kathmandu were among the earthquake-affected districts. In these regions, we report that 3.2\% $(54 / 1,686)$ of the healthy population demonstrated recent HEV exposure (through detection of HEV IgM) and we detected two donors with HEV antigen. The rate of HEV IgM prevalence was lower in the non-earthquake affected region, Chitwan, where a similar pattern was observed for HEV IgG. This suggests less HEV transmission in the Chitwan district. During an epidemic in Biratnagar, Nepal, 2014, HEV IgM prevalence was as high as $94-100 \%$ in acute hepatitis patients [11]. In our study, subjects were blood donors, considered healthy and therefore would not capture the symptomatic group of the population. HEV IgM and antigen detection are likely to represent asymptomatic infections in blood donors. Since symptomatic HEV cases are unlikely to be included, studying blood donors may result in an inability to detect the full magnitude of an outbreak. Selecting well donors may additionally result in selection bias of those with preexisting immunity in hyperendemic areas. However, given that $50 \%$ of HEV cases in developing countries are asymptomatic [3], we assume we have identified about half of the cases during this time. 
Table 1 HEV IgM seroprevalence in Nepalese blood donors

\begin{tabular}{|c|c|c|c|c|c|c|c|}
\hline \multirow[t]{2}{*}{ Variable } & \multirow[t]{2}{*}{$n$ tested } & \multicolumn{2}{|c|}{ HEV IgM seropositive } & \multicolumn{2}{|c|}{ Univariate Analysis } & \multicolumn{2}{|c|}{ Multivariate Analysis } \\
\hline & & $n$ & $\begin{array}{l}\% \\
(95 \% \mathrm{Cl})\end{array}$ & $\begin{array}{l}\text { Odds ratio } \\
(95 \% \mathrm{Cl})\end{array}$ & $p$ value & $\begin{array}{l}\text { Odds ratio } \\
(95 \% \mathrm{Cl})\end{array}$ & $p$ value \\
\hline \multicolumn{8}{|l|}{$\overline{\text { Sex }}$} \\
\hline Female & 306 & 4 & $1.3(0.0-2.6)$ & a & & & \\
\hline Male & 1,539 & 51 & $3.3(2.4-4.2)$ & $2.6(0.9-7.2)$ & $>0.05$ & & \\
\hline Age & & & & & $>0.05$ & & \\
\hline$<25$ years & 735 & 18 & $2.5(1.3-3.6)$ & a & & & \\
\hline $25-34$ years & 682 & 22 & $3.2(1.9-4.6)$ & $1.3(0.7-2.5)$ & $>0.05$ & & \\
\hline $35-44$ years & 315 & 10 & $3.2(1.2-5.1)$ & $1.3(0.6-2.9)$ & $>0.05$ & & \\
\hline $45-54$ years & 99 & 5 & $5.1(0.7-9.4)$ & $2.1(0.8-5.8)$ & $>0.05$ & & \\
\hline $55-64$ years & 14 & 0 & 0 & 0 & $>0.05$ & & \\
\hline District & & & & & $>0.05$ & & \\
\hline Bhaktapur & 135 & 6 & $4.4(1.0-7.9)$ & $7.4(0.9-61.8)$ & $>0.05$ & & \\
\hline Kavre & 116 & 3 & $2.6(0-5.47)$ & $4.2(0.4-40.9)$ & $>0.05$ & & \\
\hline Kathmandu & 1,435 & 45 & $3.1(2.2-4.0)$ & $5.12(0.7-37.4)$ & $>0.05$ & & \\
\hline Chitwan & 159 & 1 & $0.6(0-1.9)$ & $a$ & & & \\
\hline \multicolumn{8}{|l|}{ Donor status } \\
\hline Repeat & 1,265 & 40 & $3.2(2.2-4.1)$ & $1.2(0.7-2.2)$ & $>0.05$ & & \\
\hline First time & 580 & 15 & $2.6(1.3-3.9)$ & a & & & \\
\hline \multicolumn{8}{|l|}{ History of Jaundice } \\
\hline Yes & 212 & 13 & $6.1(2.9-9.4)$ & $2.6(1.4-4.9)$ & $<0.05$ & $2.5(1.3-4.7)$ & $<0.05$ \\
\hline No & 1,633 & 42 & $2.5(1.8-3.3)$ & a & & & \\
\hline \multicolumn{8}{|l|}{ Family history of jaundice } \\
\hline Yes & 226 & 8 & $3.5(1.1-6.0)$ & $1.3(0.6-2.7)$ & $>0.05$ & & \\
\hline No & 1,619 & 47 & $2.9(2.1-3.7)$ & a & & & \\
\hline Drinking Water Source & & & & & $>0.05$ & & \\
\hline Community tap & 274 & 10 & $3.7(1.4-5.9)$ & $1.01(0.3-3.04)$ & $>0.05$ & & \\
\hline Municipality & 940 & 20 & $2.1(1.2-3.1)$ & $0.57(0.2-1.4)$ & $>0.05$ & & \\
\hline Others & 296 & 14 & $4.7(2.3-7.2)$ & $1.05(0.2-5.29)$ & $>0.05$ & & \\
\hline Multiple sources & 60 & 2 & $3.3(0-7.9)$ & $1.2(0.5-3.1)$ & $>0.05$ & & \\
\hline Underground & 250 & 9 & $3.6(1.2-5.9)$ & a & & & \\
\hline Drinking water treatmen & & & & & $>0.05$ & & \\
\hline Boiling & 315 & 13 & $4.1(1.9-6.3)$ & a & & & \\
\hline Filtering & 1,030 & 30 & $2.9(1.9-3.9)$ & $0.7(0.4-1.5)$ & $>0.05$ & & \\
\hline Chemical treatment & 50 & 1 & $2.0(0-5.9)$ & $0.5(0.1-3.9)$ & $>0.05$ & & \\
\hline Multiple methods & 202 & 4 & $2.0(0.1-3.9)$ & $0.5(0.2-1.7)$ & $>0.05$ & & \\
\hline No treatment & 248 & 7 & $2.8(0.8-4.9)$ & $0.7(0.3-1.8)$ & $>0.05$ & & \\
\hline \multicolumn{8}{|l|}{ Vegetarianism } \\
\hline Yes & 1,663 & 48 & $2.9(2.1-3.7)$ & a & & & \\
\hline No & 182 & 7 & $3.9(1.1-6.6)$ & $1.4(0.6-3.2)$ & $>0.05$ & & \\
\hline
\end{tabular}


Table 1 HEV IgM seroprevalence in Nepalese blood donors (Continued)

\begin{tabular}{|c|c|c|c|c|c|c|c|}
\hline \multicolumn{8}{|c|}{ Pork consumption } \\
\hline Yes & 700 & 29 & $4.1(2.7-5.6)$ & $1.9(1.1-3.3)$ & $<0.05$ & $1.8(1.0-3.2)$ & $<0.05$ \\
\hline No & 1,145 & 26 & $2.3(1.4-3.1)$ & a & & & \\
\hline \multicolumn{8}{|c|}{ International travel } \\
\hline Yes & 565 & 15 & $2.7(1.3-4.0)$ & $a$ & & & \\
\hline No & 1,280 & 40 & $3.1(2.2-4.1)$ & $1.2(0.6-2.1)$ & $>0.05$ & & \\
\hline
\end{tabular}

${ }^{a}$ Reference group

HEV antigen, indicative of current infection, was detected in 2 donors from Kathmandu. Both of these donors were positive for $\mathrm{HEV}$ IgG, but negative for $\mathrm{HEV}$ IgM. This indicates HEV antigen is likely to persist for a short period, and is undetectable by the time of appearance of HEV IgM. A study has shown that 19\% (3/16) of HEV antigen positive samples were HEV IgM negative [27]. Concurrent detection of HEV antigen and IgG in both our donors could indicate re-infection, however, non-specificity of the antigen assay cannot be ruled out. In the absence of HEV RNA testing, the infectious state of antibody and/or antigen positive donors could not be determined.

In the absence of complete population data during epidemic and inter-epidemic periods of HEV circulation, there is no definitive IgM positivity proportion that can be used to define a recent outbreak. The majority of serological studies in epidemics are done in acute cases, and not relevant to background population seroprevalence. However, population serosurveys during known large outbreaks indicate a higher prevalence of IgM positivity than detected in our study. In Sudan in 2012 a serosurvey performed before a large outbreak peak in refugee camps demonstrated an IgM positivity rate of $21.7 \%$ [28]. Similarly, in a serosurvey of children aged

Table 2 HEV antigen positive blood donors

\begin{tabular}{lll}
\hline Variable & Sample 1059 & Sample 1303 \\
\hline Collection Date & 12/06/2015 & $13 / 06 / 2015$ \\
Collection District & Kathmandu & Kathmandu \\
Age & 36 & 36 \\
Sex & Male & Female \\
History of Jaundice & Yes & No \\
Family history of jaundice & No & No \\
Drinking water source & Municipality & Municipality \\
Vegetarianism & No & No \\
Pork Consumption & No & No response \\
International travel & No & No \\
HEV IgG & Positive & Positive \\
HEV IgM & Negative & Negative \\
HEV antigen & Positive & Positive \\
\hline
\end{tabular}

0-15 during an Ugandan outbreak, IgM positivity was $37.3 \%$ [29]. In endemic areas, asymptomatic positivity in blood donors varies from 0.5 to $5 \%$ [30-34]. Our finding of $3.2 \%$ IgM positivity in blood donors from earthquake-affected regions is consistent with ongoing endemic transmission. Therefore, we did not find strong evidence of a large post-earthquake HEV outbreak. Persistence of HEV IgG offers protection from subsequent infection; it has been observed that $\mathrm{HEV}$ outbreaks occur every few years in India, perhaps corresponding to when herd immunity drops below a threshold [35]. Thus high antibody levels present in the Nepalese population due to previous outbreaks could have provided immunity against re-infection of the exposed population.

HEV outbreaks in Nepal are either focal (where a large number of cases occur over days to weeks in a welldefined small population) or epidemic [9]. This study did not have the power to detect a focal outbreak. The failure of this study to provide evidence of a large HEV outbreak in the months directly following the earthquakes reflects either inability of the study to detect the outbreak, or the absence of a HEV outbreak. It has been estimated that 390,000 individuals left the Kathmandu region immediately following the earthquakes, with movements into the area significantly below normal [36]. These population flows may have decreased the HEV population susceptibility. If migrant populations with lower HEV immunity were disproportionately removed from the at risk population this would decrease the likelihood of an outbreak. The impact of earthquake relief support to public health threats such as provision of clean water and increased awareness of the risk may have also decreased the likelihood of an outbreak. Alternatively, given the lack of baseline HEV IgM positivity in Nepalese blood donors, it may be that $3.2 \%$ exposure represents a small outbreak. This argument is strengthened by the prolonged epidemic pattern that typically occurs in Kathmandu and the transient nature of IgM positivity [37]. However, there are no recent published reports on HEV clinical cases that would indicate an outbreak in the general population post-earthquake.

Since HEV in developing countries is commonly associated with drinking contaminated water, there is less 
Table 3 HEV IgG seroprevalence in Nepalese blood donors

\begin{tabular}{|c|c|c|c|c|c|c|c|}
\hline \multirow[t]{2}{*}{ Variable } & \multirow[t]{2}{*}{$n$ tested } & \multicolumn{2}{|c|}{ HEV IgG seropositive } & \multicolumn{2}{|c|}{ Univariate Analysis } & \multicolumn{2}{|c|}{ Multivariate Analysis } \\
\hline & & $n$ & $\begin{array}{l}\% \\
(95 \% \mathrm{Cl})\end{array}$ & $\begin{array}{l}\text { Odds ratio } \\
(95 \% \mathrm{Cl})\end{array}$ & $p$ value & $\begin{array}{l}\text { Odds ratio } \\
(95 \% \mathrm{Cl})\end{array}$ & $p$ value \\
\hline \multicolumn{8}{|l|}{ Sex } \\
\hline Female & 306 & 109 & $35.6(30.3-41.0)$ & a & & a & \\
\hline Male & 1,539 & 664 & $43.1(40.7-45.6)$ & $1.4(1.1-1.8)$ & $<0.05$ & $1.3(1.0-1.7)$ & $>0.05$ \\
\hline Age & & & & & $<0.05$ & & $<0.05$ \\
\hline$<25$ years & 735 & 155 & $21.1(18.1-24.0)$ & a & & a & \\
\hline $25-34$ years & 682 & 330 & $48.4(44.6-52.1)$ & $3.5(2.8-4.4)$ & $<0.05$ & $3.5(2.7-4.5)$ & $<0.05$ \\
\hline $35-44$ years & 315 & 203 & $64.4(59.2-69.7)$ & $6.8(5.1-9.1)$ & $<0.05$ & $7.6(5.5-10.5)$ & $<0.05$ \\
\hline $45-54$ years & 99 & 73 & $73.7(65.1-82.4)$ & $10.5(6.5-17.0)$ & $<0.05$ & $10.9(6.5-18.3)$ & $<0.05$ \\
\hline $55-64$ years & 14 & 12 & $85.7(67.4-44.2)$ & $22.5(5.0-101.4)$ & $<0.05$ & $24.6(4.9-124.3)$ & $<0.05$ \\
\hline District & & & & & $<0.05$ & & $<0.05$ \\
\hline Bhaktapur & 135 & 74 & $54.8(46.4-63.2)$ & $10.8(5.9-20.1)$ & $<0.05$ & $13.5(7.0-26.1)$ & $<0.05$ \\
\hline Kavre & 116 & 52 & $44.8(35.8-53.9)$ & $7.3(3.9-13.7)$ & $<0.05$ & $7.0(3.6-13.8)$ & $<0.05$ \\
\hline Kathmandu & 1,435 & 631 & $44.0(41.4-46.5)$ & $7.0(4.1-11.9)$ & $<0.05$ & $8.0(4.6-14.0)$ & $<0.05$ \\
\hline Chitwan & 159 & 16 & $10.1(5.4-14.7)$ & a & & a & \\
\hline \multicolumn{8}{|l|}{ Donor status } \\
\hline Repeat & 1,264 & 606 & $47.9(45.2-50.7)$ & $2.3(1.8-2.8)$ & $<0.05$ & $1.4(1.1-1.7)$ & $<0.05$ \\
\hline First time & 581 & 167 & $28.7(25.1-32.4)$ & a & & a & \\
\hline \multicolumn{8}{|l|}{ History of Jaundice } \\
\hline Yes & 213 & 119 & $55.9(49.2-62.5)$ & $1.9(1.4-2.6)$ & $<0.05$ & $2.0(1.4-2.7)$ & $<0.05$ \\
\hline No & 1,632 & 654 & $40.1(37.7-42.5)$ & a & & a & \\
\hline \multicolumn{8}{|l|}{ Family history of jaundice } \\
\hline Yes & 227 & 114 & $50.2(43.7-56.7)$ & $1.47(1.10-1.97)$ & $<0.05$ & $1.2(0.9-1.8)$ & $>0.05$ \\
\hline No & 1,618 & 659 & $40.7(38.3-43.1)$ & a & & a & \\
\hline Drinking Water Source & & & & & $<0.05$ & & $<0.05$ \\
\hline Community tap & 273 & 103 & $37.7(32.0-43.5)$ & $1.2(0.8-1.7)$ & $>0.05$ & $1.4(1.0-1.9)$ & $<0.05$ \\
\hline Municipality & 940 & 423 & $45.00(41.8-48.2)$ & $1.6(1.2-2.2)$ & $<0.05$ & $0.9(0.5-1.8)$ & $>0.05$ \\
\hline Others & 309 & 135 & $43.7(38.2-49.2)$ & $1.3(0.7-2.3)$ & $>0.05$ & $1.2(0.8-1.7)$ & $>0.05$ \\
\hline Multiple sources & 63 & 25 & $39.7(27.6-51.8)$ & $1.5(1.1-2.2)$ & $<0.05$ & $0.8(0.6-1.2)$ & $>0.05$ \\
\hline Underground & 260 & 87 & $33.5(27.7-39.2)$ & a & & a & \\
\hline Drinking water treatment & & & & & $>0.05$ & & \\
\hline Boiling & 315 & 117 & $37.1(31.8-42.5)$ & a & & & \\
\hline Filtering & 1,030 & 448 & $43.5(40.5-46.5)$ & $1.3(1.0-1.7)$ & $<0.05$ & & \\
\hline Chemical treatment & 49 & 18 & $36.7(23.2-50.2)$ & $1.0(0.5-1.9)$ & $>0.05$ & & \\
\hline Multiple methods & 203 & 91 & $44.8(38.0-51.7)$ & $1.4(1.0-2.0)$ & $>0.05$ & & \\
\hline No treatment & 248 & 99 & $39.9(33.8-46.0)$ & $1.1(0.8-1.6)$ & $>0.05$ & & \\
\hline \multicolumn{8}{|l|}{ Vegetarianism } \\
\hline Yes & 1,662 & 701 & $42.2(39.8-44.6)$ & $1.1(0.8-1.6)$ & $>0.05$ & & \\
\hline No & 183 & 72 & $39.3(32.3-46.4)$ & a & & & \\
\hline
\end{tabular}


Table 3 HEV IgG seroprevalence in Nepalese blood donors (Continued)

\begin{tabular}{|c|c|c|c|c|c|c|c|}
\hline \multicolumn{8}{|c|}{ Pork consumption } \\
\hline Yes & 701 & 323 & $46.1(42.4-49.8)$ & $1.3(1.1-1.6)$ & $<0.05$ & $1.3(1.0-1.6)$ & $<0.05$ \\
\hline No & 1,144 & 450 & $39.3(36.5-42.2)$ & a & & a & \\
\hline \multicolumn{8}{|c|}{ International travel } \\
\hline Yes & 565 & 280 & $49.6(45.4-53.7)$ & $1.6(1.3-1.9)$ & $<0.05$ & $0.9(0.7-1.2)$ & $>0.05$ \\
\hline No & 1,280 & 493 & $38.5(35.9-41.2)$ & a & & a & \\
\hline
\end{tabular}

${ }^{\mathrm{a}}$ Reference group

awareness of the potential risk of this virus to blood transfusion safety. A retrospective study in India has shown a higher prevalence of HEV infection markers among blood transfusion recipients compared to control groups [38]. HEV is a possible risk to blood supply safety in developed countries [39-41]. For developing countries, however, the main concerns are other modes of transmission, which are the major contributor to the burden of disease. However, HEV can cause chronic infection in immunocompromised individuals [17, 42], and contributes to a higher mortality rate in women during third trimester of pregnancy [3]. Hence, a safe blood supply for these high-risk vulnerable patients should also be of concern in developing countries.

Higher HEV IgG and IgM prevalence was observed in donors who reported eating pork, which is likely an indicator of zoonotic transmission [8]. HEV RNA of unknown genotype and antibodies have been detected in domestic swine in Kathmandu [19]. This suggests zoonotic transmission via consumption of undercooked pork may also contribute to the burden of $\mathrm{HEV}$ in Nepal. However, to date, isolation of HEV genotype 3 from humans associated with swine has not been reported in Nepal.

Donors' responses to drinking water source and method of water treatment were solely based on their preference and their practice of water collection and treatment. Therefore, risk from other sources of water consumed could have also contributed to seropositivity. Based on our observation, lower HEV IgG seroprevalence was associated with individuals relying on an underground water source. A potential explanation could be less likelihood of faecal contamination of underground water compared to other sources. With the drinking water pipelines being adjacent to the sewer system in the Kathmandu district, there is a chance that the drinking water could be contaminated in the event of sewer leakage. Underground water is usually sourced from deep below the earth's surface and collected directly by manual hand pumps or water pumps and therefore there is a lower possibility of contamination.

HEV IgG prevalence in the blood donor population studied was relatively high. This is in a similar range to previous estimates in Nepal based on population studies
[9, 12]. HEV IgG prevalence was highest in Bhaktapur and lowest was in Chitwan, indicating HEV exposure varies between the different regions of Nepal. Geography and other factors, such as water supply systems, in these districts are likely to contribute to these observed differences. HEV IgG prevalence increased with age, which is in agreement with studies in other countries [41, 43], and indicates cumulative exposure. However, this observation differs from previous studies in Nepal, which have shown non-uniform increase with age $[9,12]$. The variation is likely to be due to differences in cohort selection between the studies.

\section{Conclusions}

$\mathrm{HEV}$ infection in Nepalese blood donors is comparable to the general population. Past exposure to HEV was associated with multiple factors, including age, district of blood collection and consumption of pork. In developing countries like Nepal, where the main transmission route is faecal oral, other modes of transmission including zoonotic and transfusion may also occur. Detection of recent HEV infection in the donor population demonstrates the risk of transfusion-transmission in vulnerable patients in Nepal. Unexpectedly, this study did not provide evidence of a sizeable HEV outbreak after the devastating earthquakes in 2015.

\section{Abbreviations}

Cl: Confidence Interval; CBTS: Central Blood Transfusion Service; HEV: Hepatitis E Virus; IgG: Immunoglobulin G; IgM: Immunoglobulin M; NRCS: Nepal Red Cross Society; RNA: Ribonucleic Acid

\section{Acknowledgements \\ We thank staff from the Nepal Red Cross Society, Central Blood Transfusion Service (Kathmandu) and district blood transfusion services (Bhaktapur, Kavre and Chitwan) for assisting with sample collecting and testing, the blood donors who participated in this study and the members of the Brisbane Research and Development team at the Australian Red Cross Blood Service, especially Jesse Fryk and Thu Tran for technical assistance. We also thank the organisers of the International Society of Blood Transfusion working party on Transfusion Transmitted Infectious Diseases research young investigator training program, Brian Custer, Marion Vermeulen and Michael Schmidt, for providing intellectual advice.}

\section{Funding}

This work was supported by a University of Queensland International Scholarship and a University of Queensland Graduate School International Travel Award (ACS). Australian governments fund the Australian Red Cross Blood Service to provide blood, blood products and services to the 
Australian community. HEV antigen kits were provided at no charge by Prof. Dr. Y. Wang and Beijing Wantai Biological Pharmacy.

\section{Availability of data and materials}

The raw data from this study cannot be shared publicly as ethical approval was not obtained for such a purpose. The datasets used and/or analysed during the current study are available from the corresponding author on request.

\section{Authors' contributions}

ACS designed the study, performed the laboratory testing, collected and analysed the data, and, wrote the manuscript. RLPF, CRS and HMF contributed to the study design and provided intellectual support in relation to data analysis and in drafting the manuscript. VCH provided intellectual support in relation to data analysis and in drafting the manuscript. MR, SKS and UT contributed to the study design, collection of samples and data, laboratory testing and drafting of the manuscript. All authors read and approved the final manuscript.

\section{Competing interests}

The authors declare that they have no competing interests.

\section{Consent for publication}

Not applicable.

\section{Ethics approval and consent to participate}

Informed consent was obtained from participating blood donors, and details including age, sex and other variables were collected via additional questionnaire. Ethical approval was obtained from the Nepal Health Research Council and the University of Queensland Human Research Ethics Committee.

\section{Author details}

${ }^{1}$ Research and Development, Australian Red Cross Blood Service, 44 Musk Avenue, Kelvin Grove, Brisbane, QLD 4059, Australia. ${ }^{2}$ School of Medicine, The University of Queensland, 288 Herston Road, Herston, Brisbane, QLD 4006, Australia. ${ }^{3}$ Medical Services, Australian Red Cross Blood Service, Herdsman, Perth, WA 6017, Australia. ${ }^{4}$ Central Blood Transfusion Services, Nepal Red Cross Society, Kathmandu, Nepal.

\section{Received: 10 August 2016 Accepted: 16 November 2016} Published online: 25 November 2016

\section{References}

1. Teshale EH, Hu DJ, Holmberg SD. The two faces of hepatitis E virus. Clin Infect Dis. 2010;51(3):328-34.

2. Shrestha AC, Faddy HM, Flower RL, Seed CR, Keller AJ. Hepatitis E virus: do locally acquired infections in Australia necessitate laboratory testing in acute hepatitis patients with no overseas travel history? Pathology. 2015;47(2):97-100.

3. Kamar N, Dalton HR, Abravanel F, Izopet J. Hepatitis E virus infection. Clin Microbiol Rev. 2014;27(1):116-38.

4. Piper-Jenks N, Horowitz HW, Schwartz ER. Risk of Hepatitis E Infection to Travelers. J Travel Med. 2000;7:194-9.

5. Scobie L, Dalton HR. Hepatitis E: source and route of infection, clinical manifestations and new developments. J Viral Hepat. 2013;20(1):1-11.

6. Dalton HR, Stableforth W, Thurairajah P, Hazeldine S, Remnarace R, Usama W, Farrington L, Hamad N, Sieberhagen C, Ellis V, et al. Autochthonous hepatitis $\mathrm{E}$ in Southwest England: natural history, complications and seasonal variation, and hepatitis E virus lgG seroprevalence in blood donors, the elderly and patients with chronic liver disease. Eur J Gastroenterol Hepatol. 2008;20(8):784-90.

7. Borgen K, Herremans T, Duizer E, Vennema H, Rutjes S, Bosman A, de Roda Husman AM, Koopmans M. Non-travel related Hepatitis E virus genotype 3 infections in the Netherlands; a case series 2004-2006. BMC Infect Dis. 2008;8:61.

8. Colson P, Borentain P, Queyriaux B, Kaba M, Moal V, Gallian P, Heyries L, Raoult D, Gerolami R. Pig liver sausage as a source of hepatitis E virus transmission to humans. J Infect Dis. 2010;202(6):825-34.

9. Shrestha SM. Hepatitis E in Nepal. Kathmandu Univ Med J. 2006;4(4):530-44.

10. Perez-Gracia MT, Suay B, Mateos-Lindemann ML. Hepatitis E: an emerging disease. Infect Genet Evol. 2014;22:40-59.
11. Ananta S, Thupten KL, Sneha K, Deepak RS, Utsav R, Shyam KR, Mamun A-M, Kazuaki T, Masahiro A, Sheikh MFA, et al. Hepatitis E Epidemic, Biratnagar, Nepal, 2014. Emerg Infect Dis. 2015;21(4):711.

12. Izopet J, Labrique AB, Basnyat B, Dalton HR, Kmush B, Heaney CD, Nelson KE, Ahmed ZB, Zaman K, Mansuy JM, et al. Hepatitis E virus seroprevalence in three hyperendemic areas: Nepal, Bangladesh and southwest France. J Clin Virol. 2015;70:39-42.

13. Fletcher J. A traveller returning from Nepal with hepatitis E. Med J Aust. 1993;159(8):563.

14. Ibrahim AS, Alkhal A, Jacob J, Ghadban W, Almarri A. Hepatitis E in Qatar imported by expatriate workers from Nepal: epidemiological characteristics and clinical manifestations. J Med Virol. 2009;81(6):1047-51.

15. Shrestha AC, Flower RLP, Seed CR, Keller AJ, Hoad V, Harley R, Leader R, Polkinghorne B, Furlong C, Faddy HM. Hepatitis E Virus Infections in Travellers: A Threat in Australia? Vox Sang. 2015;109(Suppl2):67-8.

16. Li Y, Guo H, Xu Z, Zhou X, Zhang H, Zhang L, Miao J, Pan Y. An outbreak of norovirus gastroenteritis associated with a secondary water supply system in a factory in south China. BMC Public Health. 2013;13:283.

17. Kamar N, Bendall R, Legrand-Abravanel F, Xia N-S, ljaz S, Izopet J, Dalton HR. Hepatitis E. Lancet. 2012;379(9835):2477-88.

18. Shrestha SM, Shrestha S, Tsuda F, Nishizawa T, Gotanda Y, Takeda N, Okamoto $\mathrm{H}$. Molecular investigation of hepatitis $\mathrm{E}$ virus infection in patients with acute hepatitis in Kathmandu. Nepal J Med Virol. 2003;69(2):207-14.

19. Clayson ET, Innis BL, Myint KSA, Narupiti S, Vaughn DW, Giri S, Ranabhat P, Shrestha MP. Detection of Hepatitis E Virus Infections among Domestic Swine in the Kathmandu Valley of Nepal. Am J Trop Med Hyg. 1995;53(3): 228-32.

20. Basnyat B, Dalton HR, Kamar N, Rein DB, Labrique A, Farrar J, Piot P: Nepali earthquakes and the risk of an epidemic of hepatitis $E$. The Lancet. 2015:385(9987):2572-3.

21. Disasters Emergency Committee http://www.dec.org.uk/appeal/nepalearthquake-appeal. Date Accessed: 22 Apr 2016.

22. Kamigaki T, Seino J, Tohma K, Nukiwa-Soma N, Otani K, Oshitani H. Investigation of an Influenza A (H3N2) outbreak in evacuation centres following the Great East Japan earthquake, 2011. BMC Public Health. 2014:14:34.

23. Shrestha A, Lama TK, Gupta BP, Sapkota B, Adhikari A, Khadka S, Shrestha SM, Maharjan KG, Karmacharya P, Akbar SM. Hepatitis E virus outbreak in postearthquake Nepal: is a vaccine really needed? J Viral Hepat. 2016;23(6):492.

24. Sample size determination in health studies http://apps.who.int/iris/ bitstream/10665/40062/1/9241544058_\%28p1-p22\%29.pdf. Date Accessed: 25 May 2015.

25. The Global Prevalence of Hepatitis E Virus Infection and Susceptibility: A systematic Review http://whqlibdoc.who.int/hq/2010/WHO_IVB_10.14_ eng.pdf. Date Accessed: 28 July 2014.

26. Hepatitis - Nepal: (Kathmandu), Earthquake-related http://www.promedmail. org/direct.php?id=3338560. Date Accessed: 15 Jan 2016.

27. Wen GP, Tang ZM, Yang F, Zhang K, Ji WF, Cai W, Huang SJ, Wu T, Zhang J, Zheng ZZ, et al. A valuable antigen detection method for diagnosis of acute hepatitis E. J Clin Microbiol. 2015;53(3):782-8.

28. Thompson K, Dvorzak JL, Lagu J, Laku R, Dineen B, Schilperoord M, Muita M, Gikunju S, Waiboci L, Fields B, et al. Investigation of hepatitis E outbreak among refugees - Upper Nile, South Sudan, 2012-2013. MMWR Morb Mortal Wkly Rep. Centers for Disease Control and Prevention. 2013;62(29): $581-6$.

29. Patel RC, Kamili S, Teshale E. Hepatitis E virus infections in children age 0-15, Uganda outbreak, 2007. J Clin Virol. 2015;73:112-4.

30. Gajjar MD, Bhatnagar NM, Sonani RV, Gupta S, Patel T. Hepatitis E seroprevalence among blood donors: A pilot study from Western India. Asian J Transfus Sci. 2014:8(1):29-31.

31. Johargy AK, Mahomed MF, Khan MM, Kabrah S. Anti hepatitis E virus seropositivity in a group of male blood donors in Makkah, Saudi Arabia. J Pak Med Assoc. 2013;63(2):185-9.

32. Ma L, Sun $P$, Lin F, Wang $H$, Rong $X$, Dai $Y$, Liu J, Qian L, Fang M, Su N, et al. Prevalence of hepatitis E virus in Chinese blood donors. J Int Med Res. 2015:43(2):257-62

33. Traore KA, Ouoba JB, Rouamba H, Nebie YK, Dahourou H, Rossetto F, Traore AS, Barro N, Roques P. Hepatitis E Virus Prevalence among Blood Donors, Ouagadougou, Burkina Faso. Emerg Infect Dis. 2016;22(4):755-7.

34. Mansuy JM, Saune K, Rech H, Abravanel F, Mengelle C, L Homme S, Destruel F, Kamar N, Izopet J. Seroprevalence in blood donors reveals 
widespread, multi-source exposure to hepatitis E virus, southern France, October 2011. Euro Surveill. 2015;20(19):27-34.

35. Khuroo MS, Khuroo MS, Khuroo NS. Transmission of Hepatitis E Virus in Developing Countries. Viruses. 2016;8(9):253. doi:10.3390/v8090253.

36. Wilson R, Zu Erbach-Schoenberg E, Albert M, Power D, Tudge S, Gonzalez M, Guthrie S, Chamberlain H, Brooks C, Hughes C, et al. Rapid and Near Real- Assessments of Population Displacement Using Mobile Phone Data Following Disasters: The 2015 Nepal Earthquake. PLoS currents. 2016;8. doi: 10.1371/currents.dis.d073fbece328e4c39087bc086d694b5c.

37. Dalton HR, Bendall R, ljaz S, Banks M. Hepatitis E. an emerging infection in developed countries. Lancet Infect Dis. 2008:8(11):698-709.

38. Khuroo MS, Kamili S, Yattoo GN. Hepatitis E virus infection may be transmitted through blood transfusions in an endemic area. J Gastroenterol Hepatol. 2004;19(7):778-84.

39. Petrik J, Lozano M, Seed CR, Faddy HM, Keller AJ, Prado Scuracchio PS, Wendel S, Andonov A, Fearon M, Delage G, et al. Hepatitis E. Vox Sang. 2016;110(1):93-130.

40. Pawlotsky JM. Hepatitis E screening for blood donations: an urgent need? Lancet. 2014;384:1729-30.

41. Mansuy JM, Bendall R, Legrand-Abravanel F, Saune K, Miedouge M, Ellis V, Rech H, Destruel F, Kamar N, Dalton HR, et al. Hepatitis E virus antibodies in blood donors, France. Emerg Infect Dis. 2011;17(12):2309-12.

42. Abravanel F, Lhomme S, Chapuy-Regaud S, Mansuy J-M, Muscari F, Sallusto F, Rostaing L, Kamar N, Izopet J. Hepatitis E Virus Reinfections in Solid-OrganTransplant Recipients Can Evolve Into Chronic Infections. J Infect Dis. 2014; 209(12):1900-6.

43. Shrestha AC, Seed CR, Flower RL, Rooks KM, Keller AJ, Harley RJ, Chan HT, Holmberg JA, Faddy HM. Hepatitis E virus and implications for blood supply safety, Australia. Emerg Infect Dis. 2014;20(11):1940-2.

\section{Submit your next manuscript to BioMed Central and we will help you at every step:}

- We accept pre-submission inquiries

- Our selector tool helps you to find the most relevant journal

- We provide round the clock customer support

- Convenient online submission

- Thorough peer review

- Inclusion in PubMed and all major indexing services

- Maximum visibility for your research

Submit your manuscript at www.biomedcentral.com/submit 